\title{
Gender differences in perception of the appropriate maturity age for men and women: Age norms of reproduction-related life events between the social context and evolutionary foundations
}

Bojan Todosijević ( $\sim$ btodosijevic@idn.org.rs )

IDN

Suzana Ignjatović

IDN

\section{Research Article}

Keywords: ideal age, maturity, reproduction-related life events, gender differences, ESS, evolutionary theory

Posted Date: March 26th, 2021

DOl: https://doi.org/10.21203/rs.3.rs-337251/v2

License: (1) This work is licensed under a Creative Commons Attribution 4.0 International License.

Read Full License 


\section{Abstract}

The paper explores gender differences in the perception of appropriate age for reproduction-related life events. Evolutionary theory suggests that age norms are shaped by gender-specific evolutionary challenges. We tested two hypotheses based on the evolutionary rationale. Hypothesis 1 suggests that both men and women believe that women should reach maturity and experience reproduction-related life events earlier than men. Hypothesis 2 claims that men and women demonstrate this tendency asymmetrically. When women estimate the appropriate/ideal age for men, they suggest a higher appropriate age for men than men themselves. When men estimate the appropriate/ideal age for women, they suggest a younger age for women compared to women themselves. In the second part of the paper, we explored the background of these claims by testing the alternative explanations based on 'social forces' (culture, socio-economic status, education, age, values). The hypotheses were tested using the 9th wave of the ESS data, totaling around 47 thousand respondents and the sample of Balkan countries was analyzed in more detail. The appropriate age was measured using 'ideal age' as the concept which reflects the optimal timing expectations for reproduction-related events: living with a partner, marriage, and parenthood. Respondents were also asked to make judgments about the appropriate age of becoming an adult for men and women. The overall results supported the outlined expectations based on the evolutionary approach. The results did not provide convincing evidence for the alternative, nonevolutionary interpretation of the identified patterns.

\section{Background}

According to population statistics, there is a consistent age gap in the reproductive behavior of men and women. In Serbia, for instance, women have their first child and get married at an earlier age, on average (Statistical Office of the Republic of Serbia, 2017; 2020). These differences are caused by gender-specific age norms and expectations which have a significant role in shaping behavior over the life course, as "prods and brakes upon behavior, in some instances hastening an event, in others delaying it" (Neugarten, Moore, Lowe, 1996: 25).

Although the formal age norms (age of consent etc.) are converging across countries, there are still differences in cross-cultural perceptions of the appropriate age of maturity and reproduction-related behavior for men and women.[1] However, there is a lack of explanatory research on informal age norms and gender in the area of reproduction. One recent cross-cultural study explored the perceptions of the age of adulthood and markers of adulthood, without an in-depth gender-age elaboration (Spéder, Murinkó, Settersten, 2014). Another study considers the timing of family transitions as actual experience but lacking a normative perspective on this issue (Scherger, 2009).

This paper aims to fill the identified gap in research on age norms, gender, and reproductive behavior. The appropriate age for certain reproduction-related life events is operationalized as 'ideal age' which reflects the optimal timing expectations for reproduction-related events: living with a partner, marriage, and parenthood. Our approach departs from the explanations based on "social forces" and draws on the 
evolutionary rationale to explain the persistent prescriptive age patterns for men and women. We proceed by testing the explanatory value of the evolutionary approach as opposed to the alternative explanations based on socio-economic status, education, values, etc (e.g., Eagly and Wood 1999).

The evolutionary approach to gender, age, and reproduction

The role of evolutionary mechanisms is to 'solve adaptive problems' (Buss, Schmitt, 2011). The expressed preferences reflect evolution-based tendencies, whether conscious or not: "The human preferences of today are influenced by evolved evaluative mechanisms that had been associated with greater survival success in ancestral environments" (Huang \& Bargh, 2008, p. 573).[2] Men and women have encountered different problems in mating and sexual behavior and consequently, developed gender-specific adaptive mechanisms. From a biological perspective, pregnancy and breastfeeding are exclusively female issues, while the problems of uncertain paternity and misdirected parental investment are specific for men. In other domains, evolutionary mechanisms converged (habitat preference or kin investment) (Buss, Schmitt, 2011). The timing of adulthood/maturity and reproduction-related behavior is a robust evolutionary mechanism based on gender differences. Evolutionary theory suggests that gender/sex matters in perceptions of the age of maturity and the appropriate age for certain reproduction-related life events in two ways.

1. It depends whether the appropriate age is suggested for men or women.

On average, the appropriate age of reproduction-related events for women is lower compared to what is seen as appropriate for men. Also, the perceived age of maturity for men and women (at what age a man/woman becomes an adult) is expected to show the same pattern: women are expected to reach maturity earlier than men. What is important to note here is that both genders (sexes) are expected to share this view, estimating the lower appropriate age for women and higher for men.

Researchers described several evolutionary benefits for men to mate with relatively younger partners (Kenrick \& Keefe, 1996). They are mostly related to fertility and future reproductive potential (Kenrick \& Keefe, 1996; Pawlowski \& Dunbar, 1999). Age norms could be explained by 'sensitivity to the peak' in mating preferences (Huang \& Bargh, 2008). Women are more often evaluated for their physical characteristics and attractiveness as indicators of their reproductive value. These markers are "heuristic cues" in mating behavior and human reproduction (Huang and Bargh, 2008). Age is commonly used as a proxy in estimating maturity in mating behavior.[3] It has been confirmed that age preferences for dating partners are consistent with 'ordinary' expectations: men prefer younger women (the age gap increases with men's age) and women prefer older men (the gap being relatively constant over the life course) (Kenrick et al., 1996).

Correspondingly, given the high parental investment of human females, women are 'choosier' about a mate's characteristics (Kenrick et al, 1990). They tend to prefer males of somewhat older age compared to themselves. The evolutionary rationale is that humans have "exceptionally long periods of juvenile dependence that are partially subsidized by male economic contributions" (Hill, 1983: 86). In other words, 
for females, social status matters more and it is related to males' age. The underlying reason is that social status and resources are accumulated with age (Schmitt \& Buss, 2018, AUTHOR, 2003).

2. This asymmetric perception is further differentiated if the assessments are made by men or women. Due to the asymmetry in optimal reproductive strategies and different parental investment, the asymmetry between the genders will be increased even if they evaluate age norms for the same gender. This asymmetry reflects different sex-related evolutionary interests.

First, women are expected to perceive the ideal age for men as somewhat higher compared to what men perceive for themselves. According to Trivers's theory of parental investment, resources of a potential mate (of the opposite sex) are more relevant to the gender with greater parental investment, hence women show a greater tendency to suggest older appropriate age for men (Pawlowski \& Dunbar, 1999; Buss, Schmitt, 1993).[4] On the other side, being the sex characterized by lower parental investment, men do not feel the same pressure to assign maturity at an equally older age. For them, the preferred age gap is due to their incentive to mate with younger females. Hence, they have an incentive to think of their own sex as being sufficiently mature even if the age difference is somewhat lower compared to what females opine. The benefits are, for instance, the increased choice of potential mates, and especially the possibility to start mating at an earlier age and therefore have a longer mating period over the lifecourse[5]. For the sex with less parental investment, it should pay off to mate even if the chance of offspring survival is smaller due to its lack of resources to contribute to the offspring's survival.

Second, compared to women, men are expected to perceive the maturity age of women to be lower. A corresponding asymmetry is expected to be relevant for the sex with greater parental investment (women, speaking of homo sapiens). For women, an important strategic goal is to secure a resourceful mate, willing to share and invest resources in joint offspring (e.g., Schmitt \& Buss, 2018). It may be required to have sufficient time to make an appropriate choice, to avoid choosing a too young ergo resource-poor mate, and perhaps more importantly, to reach the age of the highest fertility (which is associated with somewhat older age compared to the long-term cumulative fertility). Thus, from the angle of the female long-term reproductive strategy, there is less pressure to secure a mate at the earliest age, but only not to miss the peak of the mating value.[6] From the male angle, the ideal mate, especially taking into account the evolutionary imperative of paternal certainty, as well as cumulative fertility, is a partner close to the age of physiological maturity, i.e., clearly below the age of what would female optimal mating strategy advise as ideal for their own sex/gender.

The bulk of the evolutionary psychology literature focuses on the first hypothesis - simple sex differences in the perceived ideal or appropriate age for reproduction-related life-course events. We want to expand the evolutionary conceptual framework, by proposing the second hypothesis - that it matters not only about whom the judgments are made (men or women) but also by whom. To summarize our theoretical argument, we expect (1) that both genders agree that the ideal/appropriate age to start living with a partner (become adult, get married, become a parent) for women is lower than for men, and (2) that men and women differ in the perceptions of ideal age for their own and the opposite sex. (2a) Men 
are expected to think that the ideal age for women is lower than what women would think. (2b) Women are expected to think that the ideal age for men is somewhat higher compared to what men think.

The above hypotheses are tested on the questions about reproduction-related life-course events. We expect to find some converging patterns, while the ideal ages for these events may differ. For instance, the maturity age is expected to be lower compared to the ideal age to become a parent. Likewise, the ideal age to get married is likely to be higher compared to the ideal age for starting living with a partner. Yet, the pattern of the relationships should be equivalent in each case. The ideal age for women is to be estimated as younger compared to the age of men, the perceptions expressed by men and by women should be asymmetric - as described above.

Finally, it has been noted that for humans, mating strategies and preferences are influenced by long-term and short-term perspectives (Wiederman \& Dubois, 1998). For instance, it has been reported that in a short-term context, men's standards are considerably lower than their standards for a long-term mate, while women's standards in both contexts are similar (Kenrick et al.1990, 1993; Nevid 1984). In our research, the question referring to the age of becoming an adult does not differentiate between short-term or long-term goals. The other three questions (ideal age to start living with a partner, to get married, and to become a parent) all imply a long-term relationship. To some extent, the question on the 'ideal age to start living together unmarried' is perhaps somewhat ambiguous concerning the time perspective. However, the phrase 'living together' (rather than just 'dating' for instance) also suggests a long-time perspective. This is important, because the implications from the parental investment theory, as well as Sexual Strategies Theory (Buss and Schmitt 1993), are more dealing with a long-term context. For instance, in a short-term context, distinctive male preference for women of younger age is likely to be attenuated (Kenrick et al. 1990).

[1] In this paper, we use the term 'maturity', which partly overlaps with the 'transition to adulthood', but it is more suitable for evolutionary discourse. Also, the concepts of 'sex' and 'gender' are used interchangeably. Of course, we are aware that these conceptual subtleties may create different interpretations of the subject matter.

[2] What happens in practice may however differ from the evolutionary-grounded preferences, for various reasons. What is often observed, for instance, is that older men tend to marry older women, including those who are post-menopausal, despite their stated preferences for younger women. However, when South Korean men marry 'purchased brides', they seem to more freely act on their preferences, and therefore actually marry young, fertile women, regardless of whether grooms are young or old (Sohn, 2017).

[3] However, this is a fine-grained mechanism: the appropriate age of maturity has its upper and lower limits and corresponds to the peak of reproductive value combined with the highest chances of survival (Hill, 1983).

[4] Parental investment is defined as "any investment by the parent in an individual offspring that increases the offspring's chances of surviving (and hence reproducing) at the cost of the parent's ability to invest in other offspring" (Trivers, 1972, p. 139. as cited in Buss, Schmitt, 1993: 206). 
Actually, the potential male mate should not be neither too young nor too old: "this is because they [females] need to ensure that any male partner is neither too young (either because he is unlikely to accumulate sufficient wealth during the woman's active reproductive life or because he is more likely to desert in favour of younger women) nor too old (because of the increased risk that he will die prematurely before the end of the period of parental investment)" (Pawlowski \& Dunbar, 1999, p. 66).

[5] Buss, Shackelford, and LeBlanc (2000), for instance, report that men (but not women) prefer younger partners the more children they desire to have.

[6] As Huang \& Bargh argue, "Because human mate value is based in part on the age of a potential mate, sensitivity to the peak is paramount." (Huang \& Bargh, 2008, 573).

\section{Method}

The analysis is based on the data from the European Social Survey (Round 9). The interviews were conducted in 29 European countries in 2018, using the CAPI interview mode. In each country, the ESS surveys are based on nationally representative random samples. The complete ESS 9 dataset (Edition 2, Production date: $15 / 06 / 2020$ ) includes around 47,000 respondents. Some analyses in this paper are based on the entire ESS sample and some analyses are limited to individual countries.

We used a set of questions from the "Timing of Life" Module, which was first introduced in Round 3 as a rotating module (2006). The module is based on a multidisciplinary life course perspective (European Social Survey, 2018).[7] The questions are designed to differentiate between the real-life experience ("Are you or have you ever been married?") and normative aspects of the life course ("In your opinion, what is the ideal age for a boy or man to get married?"). We are interested in the questions addressing the age norms of maturity/adulthood and reproduction-related life events.

Survey design

The subset of questions was administered through a split ballot survey design. Half of the randomly selected respondents were asked about women, the other half about men. Hence, there are two sources of differences between the genders. First, men and women have different views of age norms of life events (respondent gender). Second, men and women have different views of male and female age norms of life-course events (gender by questions asked). Hence, the sample is divided into 4 categories (Table 1).

Table 1. Split ballot sampling (Module: 'Timing of Life')

\begin{tabular}{|l|r|r|r|}
\hline & \multicolumn{2}{|c|}{ Respondent gender } & \\
\cline { 2 - 3 } Gender by the question asked & Male & Female & Total \\
\hline 1. Men asked about Women & 10,992 & 0 & 10,992 \\
\hline 2. Men asked about Men & 10,758 & 0 & 10,758 \\
\hline 3. Women asked about Women & 0 & 12,815 & 12,815 \\
\hline 4. Women asked about Men & 0 & 12,516 & 12,516 \\
\hline Total & 21,750 & 25,331 & 47,081 \\
\hline
\end{tabular}


A split ballot design is suitable for testing the main hypotheses of our research. It differentiates between the expectations for men and women (ideal age norms) and possible explanatory factors of these expectations (gender and other characteristics of the interviewed participants). However, such a design has certain limits because each respondent was asked (randomly) about either male or female age norms. While this means that we cannot assess the intra-individual differences in perceptions, the adopted design ensures that assessments of the ideal or appropriate age are made independently.

Variables

Our analysis is based on a set of questions aimed to explore the ideal age of several reproduction-related life-course events and age of maturity:

Appropriate age

- Age at which girls/boys or women/men become adults,

Ideal age

- The ideal age to start living with a partner not married to,

- The ideal age to get married,

- The ideal age to become a mother/father.

Example question (ageadlt):

People differ in their ideas about the ages at which girls/boys or women/men become adults, middleaged and old.

At what age, approximately, would you say girls/boys or women/men become adults?

Interviewer instruction: If the respondent states 'It depends' accept answer and do NOT probe. If respondent provides an age range, ask for a specific age within that range. If respondent cannot give specific age, code as 'Don't know'.

Note that from the analyses reported here, we excluded those who answered 'It depends', and 'Don't know', as well as the responses below 13 and above 89 years of age, because they are treated as errors or irrelevant that would not have an impact on the results. In the analysis of the entire ESS 9 dataset, we used the provided 'analysis weight' (anweight) to enable generalizations based on the sample of "Europeans" (as represented by the ESS 9 non-random sample of countries).[8]

Hypotheses

Two hypotheses were tested: 
$\mathrm{H} 1$ : On average, the appropriate age of maturity is different for women and men: women should reach maturity and experience reproduction-related life events earlier than men.

$\mathrm{H} 2$ : Men and women should demonstrate this tendency in an asymmetric fashion. When women estimate the appropriate/ideal age for men, they should show a greater tendency to suggest older appropriate age for men. When men estimate the appropriate/ideal age for women, they should show a greater tendency to suggest younger age for women.

Alternative explanations

$\mathrm{H} 1$ (and to some extent $\mathrm{H} 2$ ) is predicted not only by the evolutionary theory but could be supported by sociological and life course research. Many studies found gender differences over the life course (AUTHOR, 2009, AUTHOR, 2006, 2010; Stanojević, Tomanović, Ljubičić, 2016; Galland, 2000). To test the robustness of the evolutionary perspective, we explored several alternative explanations of the observed findings, much of which could be subsumed under the social role theory of sex differences (Eagly and Wood 1999). Any significant variations caused by social, economic, cultural factors would reduce the heuristic value of the evolutionary explanation. We selected key variables from the dataset to test the alternative explanations (macro-level factors, education, age, values). If confirmed, this would imply that other factors are at play, rather than (just) the evolutionary forces.

[7] The module addresses four aspects of the life course: 1) the actual, experienced life events; 2) the segmentation of the life course; 3) social norms; 4) life planning (European Social Survey, 2018).

[8] According to the ESS Guide to Using Weights and Sample Design Indicators with ESS Data, the "anweight corrects for differential selection probabilities within each country as specified by sample design, for nonresponse, for noncoverage, and for sampling error related to the four post-stratification variables, and takes into account differences in population size across countries" (p. 4).

\section{Results}

Age of becoming an adult for women/men

Overall, mean estimates of the age at which boys and girls become adults differ - the respondents (mixed sexes) think that girls become adults at an age of approximately 19.8, while the average opinion is that boys become adults at approximately 22 . When taken together, men and women on average think that females become adults at a younger age compared to males. The difference is about 2 years.

More informative than the simple means is the distribution of the respondents' assessment of the age at which men/boys and women/girls become adults is presented in Figure 1. Both men and women are most likely to claim that age at which girls become adults is 18 .

The three most typical answers about that age for boys are 18,20 , and 25 . Clearly, the overall perception is that girls become adults earlier than boys. In the case of girls, some $20 \%$ of male respondents think 
that they become adults even before the age of 18 .

Women, on the other side, are more likely to cite a higher age when boys become adults. Nearly $10 \%$ of female respondents think that this age is 30 , and nearly $20 \%$ think it is the age of 25 .

The next question is whether the asymmetry in perceptions by male and female respondents as predicted by our Hypothesis 2 and noticed in the above figure, is also statistically significant. The average perceived age at which girls and boys become adults (by male and female respondents) is presented in Figure 2. The graph also shows the confidence intervals around the estimated means.

Compared to female respondents, men think that girls become adults at a younger age (19.6), while female respondents give a slightly higher age (20.05). The difference between males' and female respondents' estimates is larger concerning the age at which boys become adults. Male respondents, on average, proposed the age of 21.2, while women thought it should be more than a year higher (22.5). This confirms our Hypothesis 2 about the gender asymmetry in perceptions of appropriate age for boys and girls in this case.

The ideal age to start living with a partner not married to

The results indicate a relatively lower ideal age for women than for men. When asked about women, both sexes favor a somewhat younger age, 18 and 20, although the modal value is 25 years (except for men asked about women, where the modal value is 20 ). Sex differences are particularly noticeable at the extremes. Ages 18 and 20 are seen as ideal more often for women, while ages from 25 to 30 are more often seen as ideal for men. In accordance with $\mathrm{H} 1$, both genders think that the ideal age is lower for women than for men.

Concerning the sex-based asymmetry in the perceptions of the ideal age, women think that the appropriate age for men is somewhat higher than what men think is ideal for men. The highest peak at the age scale point 25 is the appropriate age for men perceived by women, similarly as for each year until 30 .

The corresponding asymmetry can be observed in the young age categories. There, men are more often among those seeing that young age as ideal for girls. In brief, women think that the ideal age for men is higher than what men think is ideal for men. Symmetrically, men think that the ideal age for women is younger than what women themselves think.

The following graphs (Figure 4) shows that gender matters two-ways:

1. Both genders think that the ideal age to start living with a partner not married to is lower for women than for men.

2. While both genders show this tendency, women think that the ideal age for men is higher than what men think is ideal for men. Symmetrically, men think that the ideal age for women is younger than what 
women themselves think.

While these gender-based comparisons produce statistically significant differences in the entire ESS sample, one may rightly ask whether these differences are substantively large as well, or the statistical inferences just reflect the large $\mathrm{N}$ ? Of course, for individual countries, confidence intervals are broader, and in some cases, some differences may be insignificant.

Figure 4 illustrates this point. The pattern of the group averages is the same as in the entire ESS sample, but in the Serbian sample, since the confidence intervals are broader some differences are not statistically significant. In this case, the difference between perceptions of the ideal age for girls by Serbian men and women is not statistically significant.

We conducted analyses for each country. While the pattern of the distribution of the means is pretty constant, some of the comparisons do produce overlapping confidence intervals. Differences between ideal ages for men and women ascribed jointly by both genders are virtually always large and significant. The interaction between genders of the perceivers and the targets is not always significant, but the pattern of relationships is pretty constant. There are two exceptions. In the Czech Republic, men opted for higher ideal age to women than female respondents did for women. Similar is the case in Latvia. In fact, in the Latvian sample, the only differing group is women's perception of ideal age for girls - which was estimated as lower than for any other group, while at the same time there were no differences between the remaining three groups. This is the only case where women gave lower ideal age for girls than men. It remains for further research to verify if this is a feature of Latvians' attitudes, or perhaps a methodological artifact.

From the evolutionary point of view, countries as units are not relevant - the evolution-based tendencies are supposed to show up regardless of political borders. Hence, the most relevant is the 'European' sample. Still, the country-level analyses may be interesting and useful for testing some of the implications, as will be shown in the subsequent sections.

The ideal age for a man/woman to get married and become a father/mother

For questions about the ideal age to get married and to become a mother/father, we present the results together. The group averages, with confidence intervals, are presented in Figure 5. The previously observed pattern is identified here as well. The respondents believe that the ideal age to get married or become a parent is higher for men than for women. The overall difference is about 2 years for both variables.

Additionally, the gender of the respondents also matters. Women attributed a higher ideal age for men compared to male respondents. On average, the ideal age for men to get married is 27.6 years, and to become a father 28.8 years. The average ideal age estimated by men is 26.9 and 28 , which is about 7-8 months lower. 
Ideal ages for women to get married and to become mothers, as perceived by men, is as low as 25.2 and 26.3, respectively. Women are somewhat less enthusiastic about getting married or becoming mothers at such a young age, so their average perception of the ideal ages is 25.9 and 26.8. The difference is about 5-7 months.

When we compare what the opposite sexes say about the ideal age of the opposite sex, we obtain a difference of averages of approximately 2.5 years. So, the average European man thinks the ideal age for a woman to get married is about 25.2 years, while the average European woman thinks the ideal age for men to get married is 27.6. In fact, ideal age norms are close to the reported behavior patterns. According to population statistics, the difference between men and women regarding their age at first marriage was, on average, around three years during 2015-2019 (Statistical Office of the Republic of Serbia, 2020).

Testing the alternative (non-evolutionary) explanations

The results presented in the previous sections are in line with the predictions based on the evolutionary approach, such as the 'parental investment theory' (Trivers, 1972). However, the results may be explainable from other perspectives. The findings might reflect the macro-level socio-cultural, economic, or political differences among the compared countries. Accounting for these differences might change the pattern of associations hypothetically caused by evolutionary inclinations.

Macro-level socio-economic and cultural factors have a strong influence on gender relations in society. It is possible that different 'gender regimes' and different opportunities for women shape the perceptions of appropriate age in reproductive behavior and maturity.[9]

Micro-level socio-economic interests may have an impact, too. According to the exchange theory, mate selection is a transaction: men and women exchange valuable resources - youth and attractiveness for resources (Taylor\& Glenn, 1976, McClintock, 2014). If this is the case, indicators of the relevant resources should matter - in particular age and education. Hence, we examined whether age and level of education affect the pattern of the obtained findings.

Finally, it could be argued that the observed gender differences and asymmetries reflect the influence of specific value orientations. In particular, the traditionalist value orientation may be responsible for differences in perceptions of the appropriate/ideal age for men and women. Non-traditionalists demonstrate age egalitarianism in their perceptions of the appropriate and ideal age for reproductionrelated events. If that is the case, the evolutionary theory would lose its explanatory value.

Macro-level factors: Culture, economy

To capture the role of broad cultural and economic factors, we treat country of residence as a summary variable encompassing the general influence of macro-level factors. We compared a group of Balkan countries (Serbia, Croatia, Montenegro, and Bulgaria) with a group of Western and Nordic countries (Sweden, Norway, Netherlands, and Switzerland). The Balkan countries are based on traditionalism modified by ex-communist experience and socio-economic transition. The Western-Nordic countries are 
liberal, high-income countries with a high quality of life.[10] Also, there is a two-way interaction between cultural change and economic development (Inglehart, Norris, 2003). The comprehensive social modernization (higher income, public services, etc.) creates "a climate conducive to more liberal views of social roles, including those determined by sex, class, and ethnicity" (Inglehart, Norris, 2003: 36). Hence, and in line with the social role theory, one would expect smaller sex differences in gender-egalitarian cultures (Eagly and Wood 1999).

The results based on the question "Age at which girls/boys or women/men become adults" are presented in Figure 6 and Figure 7. The age of becoming an adult is generally perceived to be lower in the WesternNordic group compared to the Balkan group. Although some comparisons did not produce statistically significant differences, the familiar pattern of diverging sex differences was identified. Macro-level factors do not affect the interaction between the perceiver-gender and the target-gender when evaluating the age of becoming an adult.

\section{Education}

Education could be relevant for reproduction-related preferences in multiple ways. Education may imply cultural differences - the less educated are likely inclined towards traditionalism and gender asymmetry in social relations. The level of education also implies different economic interests as the less educated are also less well-off economically. Also, extended education is associated with delayed parenthood, so it is likely to affect ideal age perceptions and reproduction-related norms (AUTHOR, 2018).

The analysis was conducted on the created variable with three education categories. Results presented in Figure 8 corroborate the argument that education is likely to affect the views on ideal age. The estimated ideal age to become a parent and ideal age to get married are strongly associated with education. The higher-educated respondents, on average, think that the ideal age for parenthood is nearly two years higher compared to the lower-educated respondents. The association between age and education is less straightforward for the remaining two variables (age of becoming adult, and ideal age to start living with a partner). This tendency may be explained by the influence of one's personal experience and perspective - parenthood is postponed until after completing education.

The main question is whether education affects the way male and female respondents perceive the ideal age for men and women. The comparison of the four gender-based groups is presented in Figure 9. The same analysis is performed in each of the three subsamples based on the level of education. The less educated believe that younger age is ideal for becoming a parent compared to respondents with higher education. But the pattern persists within the education levels. In other words, gender differences and asymmetry are not affected by education.

Age

Age is related to many other factors: socioeconomic position, personal attitudes and preferences of social norms regulating reproduction, and value orientations. Perhaps the actual position along the age 
dimension is relevant. For instance, for the youngest generations, the acceptable age range of potential mates is limited. Both 19-year-old men and women are likely to have more similar age preferences than 30 -year-old men and women - simply because a greater age range is acceptable.

In the analyzed dataset, the age of respondents is correlated with some of the examined attitudes: age is negatively correlated with the assessed ideal age to get married $(r=-.13, p<.001)$, and the perceived ideal age to become a parent $(r=-.10, p<.001)$. Thus, older respondents favor slightly younger age as ideal in these cases. But respondent's age only partly explains the pattern of interaction with gender differences and asymmetries. In most age groups, the pattern of the associations is unaffected - gender matters both for targets and evaluators. The only deviation is observed in the youngest age category (15-24 years old), where the gender asymmetry is not identified. In this category, respondents still assign higher ideal age to become a parent to men, but male and female respondents do not differ in this regard - they provided equal assessments of the ideal ages.

This may reflect the specific life-cycle position of this group - at the stage before becoming a parent. In fact, this age category gave the highest estimates of the ideal age compared to respondents from the other age categories. This could also be a generational feature. Younger generations are more inclined towards egalitarian gender relations (Inglehart, Norris, 2003). However, this deviation does not characterize all the examined attitudes. In the case of estimates of the ideal age to start living with a partner not married to, the gender difference in the assignment of the ideal age for women is reproduced in the youngest age category as well (graph not shown). So, this deviation (the lack of evidence about the gender asymmetry at the youngest cohort) is not consistently obtained across different attitudes.

This finding is partly supported by other similar studies. Kenrick et al. (1996) observed a preference among teenage boys to date women older than themselves, unlike the expected behavior, confirmed as a universal male preference for younger women. This pattern is consistent with our research results: age is associated with the assessment of ideal age for parenthood across different age categories, except for the youngest cohort (15-24). The asymmetry of gender differences between male and female respondents (higher ideal age for men when assessed by women and younger age for women when assessed by men) was not identified among the youngest men and women. We suggest that this is mainly due to the objectively restricted range.

\section{Values}

The role of values was already mentioned in the section on macro-level factors - education and age. Traditionalism in particular may be relevant, as this value orientation is explicitly interested in gender and reproduction-related domains. In this analysis, we focus on two indicators on the individual level of traditionalism. One is a self-description question, where the respondent describes him/herself in terms of specific value orientation. The respective item, which comes from the Schwartz' 'Human Values Scale', is formulated in the following manner: 
Now I will briefly describe some people. Please listen to each description and tell me how much each person is or is not like you.

Tradition is important to her/him. She/he tries to follow the customs handed down by her/his religion or her/his family.

Responses from: 1. Very much like me to 6. Not like me at all.

This variable is generally correlated with the examined attitudes about the ideal and appropriate age, but gender differences and asymmetries are not affected by traditionalism. As Figure 10 shows, the pattern of associations is equivalent both within the subsamples of the traditionalist and non-traditionalist respondents. The average age levels differ - traditionalists believe that both boys and girls tend to become adults at a slightly older age. But the two-way gender differences are persistent - men ascribe younger age to women, while women ascribe older appropriate age for men. The same pattern of associations (all equally statistically significant) for the remaining attitudes about ideal age.

The second indicator of a traditionalist worldview is identified by the following question (freehms):

Using this card, please say to what extent you agree or disagree with each of the following statements.

Gay men and lesbians should be free to live their own life as they wish

There is a strong negative correlation between this measure of traditionalism and attitudes about the ideal and appropriate age. Liberals perceive a relatively older age as ideal (close to 28) compared to those who strongly disagree with this statement (average ideal age is evaluated at slightly above 26). And yet, according to the results presented in Figure 11, the pattern of gender differences and asymmetries is unaffected. Among both traditionalists and non-traditionalists, when women are asked about the ideal age for men to start living with a partner, they opt for older age compared to men. Likewise, when men are asked about the ideal age for women, they provide a lower figure than women. However, in the traditionalist group, the differences in judgments made by men or women, are somewhat attenuated (below statistical significance in case of the ideal age for becoming a parent). Similar results obtain for several other 'ideal age' variables (perceived age when boys/girls become adults, the ideal age to get married or become a parent).

It is possible that strong value commitments may, to some extent, override the manifestation of evolutionbased tendencies. But, among the more liberal segment of the population, these tendencies are free to manifest. Still, the asymmetry affected is one concerning the ideal or appropriate age for women, but not for men. This may be partly explained by the new 'gender contract' which is part of the liberal worldview. Egalitarian gender relations are based on women's economic and political empowerment. However, unlike the 'social' role of men in evolutionary preferences, which is increasingly losing its evolutionary rationale (the role of a 'male breadwinner'), female age is still more dependent on biology, even though new options are emerging for women (based on reproductive technologies). In general, secularization and selfexpression values are associated with the decline of the traditional family and gender equality, 
respectively (Inglehart, Norris, 2003: 11). Yet, control for none of the variables that imply cultural differences, individual or societal level, erased the predicted sex differences. As Schmitt (2015) concluded, and contrary to the social role theory (Eagly and Wood 1999), evolutionary-predicted gender differences are not smaller, or disappearing, in gender-egalitarian societies or much affected by individual differences in traditionalist values.

It should also be noted that in the ESS sample, the proportion of traditionalists (in this way defined) is rather low. Namely, nearly $80 \%$ of the respondents agree or strongly agree with the statement "Gays and lesbians free to live life as they wish". An additional $10 \%$ neither agrees nor disagrees. This means that confidence intervals for averages in the traditionalist group are quite larger. If we add 'the undecided' to the traditionalist group, the asymmetry turns out to be statistically significant (the differences in ideal age perception about women, as expressed by male and female respondents).

[9] The 'gender regime' reflects the transformations of gender relations in society on the 'overall social system' based on the following dimensions: a continuum from domestic to public, the degree of gender inequality, gender relations in different domains (economic, polity, civil society) and social practices (Walby, 2004). According to Walby, there is an ongoing transformation of the gender regime from domestic to public, through several trajectories: welfare state-led, market-led, regulatory polity-led. The four countries in our analysis are mostly welfare state-led countries (except for Switzerland).

[10] According to the UN classification, the four Western-Nordic countries are 'developed economies', including Bulgaria and Croatia as part of the EU. Serbia and Montenegro are 'economies in transition'. However, ex-communist experience and cultural background are shared by these four countries in the second group (United Nations, 2020).

\section{Discussion}

Based on the evolutionary theory, we predicted that the estimated appropriate age of maturity for reproduction-related life course events will be different for men or women. We also predicted that the difference will be affected by the gender of the perceiver. Namely, men are expected to ascribe maturity (or ideal age to get married, start living with a partner) to girls/women at an earlier age compared to women. Correspondingly, women are predicted to declare higher age of maturity for men compared to men themselves. The rationale for these predictions come from Trivers' parental investment theory (1972), and Sexual Strategies Theory (Buss and Schmitt 1993, Schmitt \& Buss 2018).

We tested the implications of this theoretical approach, using the ESS 9 (2nd advance release) dataset. The ESS used a split-ballot design and asked a random half of the sample to make judgments about men and another half about women. We adopted the most simple and straightforward approach by comparing the averages of men and women making judgments about the ideal age for men and women.

Predictions from evolutionary psychology are supported by the data. We observed a complex interaction of the perception of ideal (and appropriate) age for reproduction-related activities and gender (gender of the perceiver and gender of the judgment targets). The results supported Hypothesis 1 by showing 
different ideal/appropriate ages for men and women. The European public agrees that women reach maturity earlier than men and that the ideal age for them to start living with a partner, get married, and become mothers is lower than for men. This conclusion is based on both analysis of the ESS data as a whole and each country studied separately. All evidence points to the same conclusion.

A more challenging task was to provide evidence of the gender asymmetry in the judgments of appropriate age made by male and female respondents (Hypothesis 2 ). The overall results supported the hypothesis about the gender asymmetry in all questions referring to perceptions of age-related reproductive life-cycle events - the age at which girls and boys become adults, the ideal age to start living with a partner, the ideal age to become a parent, and to get married. The specific pattern of group differences was obtained using the entire ESS 9 E02 sample, but also in most cases of specific country samples. Thus, we conclude that our Hypothesis 2 also received strong support.

However, the gender effect on differing perceptions is on theoretical grounds expected to be smaller than the effect subsumed under $\mathrm{H} 1$. H1 states that the appropriate/ideal age should differ for the two sexes. $\mathrm{H} 2$ is like a corollary to this thesis. It states that perceivers' gender also matters, and in specific directions.

One modification of the outlined interpretation of the results could be that women simply provide higher age estimates, whether it concerns ideal/appropriate age for men or women. In fact, this is the case. For each of the four questions examined, women provided higher age figures when target genders were mixed. This could be interpreted in the sense that women, being more resource-conscious, overall tend to favor a more mature age for reproduction-related life-course events.

We, however, favor the previously offered interpretation, finding that it is closer to the spirit of the evolutionary arguments about reproductive and mating strategies. Female strategy leads to pushing up the age requirement, especially for potential male partners. The male strategy is focused on potential partner's youth. In fact, both interpretations rely on the same underlying principles, differing only in the emphasis.

To test the explanatory potential of the evolutionary approach, we examined the most common alternative accounts of the observed findings. We started with the macro level, taking countries in which respondents are nested as units representing broad cultural factors, as well as socio-economic ones. We continued with the examination of the effects of education, age, and the traditionalist value orientation. None of these tests of the robustness of our findings lead to the modification of the conclusions. The same patterns are found in the subset of gender-egalitarian Western-Nordic countries as well as in more traditionalist, and less-developed Balkan countries, thus fitting Schmitt's (2015) conclusions. We also found that controlling for age and education on an individual level does not modify the group differences significantly. The same goes for the effect of the two indicators of traditionalist value orientation.

In several instances, however, a deviation from the pattern was observed. It concerns the absence of statistically insignificant differences in perceptions of the ideal/appropriate age for women, made by male and female respondents (although the reversed difference appeared in none of the cases). One 
possible explanation may a 'floor effect' because the range of preferred age is more limited at the young age end. Also, this feature may indicate substantive processes. Namely, the gender difference is more pronounced in judgments about ideal/maturity age for men. The female strategy suggests looking for a more mature and resourceful mate. The male strategy is not to abstain until resources are secured.

Concerning the perception of the ideal age for women, neither reproductive strategy suggests a more extended delay of mate selection. It remains for future research to focus more on this particular implication of our findings.

Finally, there is also a statistical reason for the lack of statistical significance in perceptions of ideal/appropriate age for women. This was found either in single-country analyses, or when controlling for the role of third variables. In both cases, this means a smaller number of respondents in particular categories, and therefore broader confidence intervals (reduced statistical power).

Future research on this topic should be extended in two directions - it should include more cases, from a more diverse cultural background. We studied a subset of European countries, which is culturally diverse, yet a homogenous background from a global perspective. Further research should develop alternative explanations by introducing additional variables and more complex models. From an evolutionary perspective, age may lose its role as a 'heuristic cue' in human reproduction because gender relations are changing. After all, the fertility age span has increased and new options are provided by technology. Notwithstanding these ongoing trends, the presented findings indicate that age still matters in reproduction-related expectations for men and women.

\section{References}

AUTHOR. 2003.

AUTHOR. 2006.

AUTHOR. 2009.

AUTHOR. 2010.

AUTHOR, 2018.

Buss, D. M., \& Schmitt, D. P. 1993. Sexual Strategies Theory: An evolutionary perspective on human mating. Psychological Review, 100(2): 204-232.

Buss, D. M., \& Schmitt, D. P. 2011. Evolutionary psychology and feminism. Sex Roles, 64(9-10): 768.

Buss, D. M., Shackelford, T. K., \& LeBlanc, G. J. 2000. Number of children desired and preferred spousal age difference: context-specific mate preference patterns across 37 cultures. Evolution and Human Behavior, 21(5): 323-331. 
Eagly, A. H., \& Wood, W. 1999. The origins of sex differences in human behavior: Evolved dispositions versus social roles. American Psychologist, 54, 408-423.

European Social Survey. 2018. ESS Round 9 Module on Timing of Life - Question Design Final Module in Template. London: ESS ERIC Headquarters c/o City, University of London.

Galland, O. 2000. Entrer dans la vie adulte: des étapes toujours plus tardives, mais resserrées. Économie et statistique, 337(1): 13-36.

Hill, K. 1993. Life history theory and evolutionary anthropology. Evolutionary Anthropology: Issues, News, and Reviews, 2(3): 78-88.

Huang, J. Y., \& Bargh, J. A. 2008. Peak of desire: Activating the mating goal changes life-stage preferences across living kinds. Psychological Science, 19(6): 573-578. https://doi.org/10.1111/j.14679280.2008.02125.x

Inglehart, R., \& Norris, P. 2003. Rising Tide. Cambridge, MA: Cambridge University Press.

Kenrick, D. T., Keefe, R. C., Gabrielidis, C., \& Cornelius, J. S. 1996. Adolescents' age preferences for dating partners: Support for an evolutionary model of life-history strategies. Child development, 67(4): 14991511.

Kenrick, D. T., Groth, G. E., Trost, M. R., \& Sadalla, E. K. 1993. Integrating evolutionary and social exchange perspectives on relationships: Effects of gender, self-appraisal, and involvement level on mate selection criteria. Journal of Personality and Social Psychology, 64(6): 951.

Kenrick, D. T., Sadalla, E. K., Groth, G., \& Trost, M. R. 1990. Evolution, traits, and the stages of human courtship: Qualifying the parental investment model. Journal of personality, 58(1), 97-116.

Nevid, J. S. 1984. Sex differences in factors of romantic attraction. Sex Roles, 11(5-6): 401-411.

McClintock, E. A. 2014. Beauty and status: The illusion of exchange in partner selection?. American Sociological Review, 79(4): 575-604.

Neugarten, B., Moore, J., Lowe, J. 1996. Age norms, age constraints, and adult socialization. In: B. L. Neugarten (Ed.), The meanings of age: Selected papers of Bernice L. Neugarten. Chicago: University of Chicago Press.

Pawlowski, B., \& Dunbar, R. I. 1999. Withholding age as putative deception in mate search tactics. Evolution and Human Behavior, 20(1): 53-69.

Scherger, S. 2009. Social change and the timing of family transitions in West Germany: Evidence from cohort comparisons. Time \& Society, 18(1): 106-129. 
Schmitt D. P. 2015. The Evolution of Culturally-Variable Sex Differences: Men and Women Are Not Always Different, but When They Are...It Appears Not to Result from Patriarchy or Sex Role Socialization. In: Shackelford T., Hansen R. (eds) The Evolution of Sexuality. Evolutionary Psychology. Springer, Cham, pp. 221-256. https://doi.org/10.1007/978-3-319-09384-0_11

Schmitt D.P., \& Buss D.M. 2018. Sex Differences in Long-Term Mating Preferences. In: Shackelford T., Weekes-Shackelford V. (eds) Encyclopedia of Evolutionary Psychological Science. Springer, Cham. https://doi.org/10.1007/978-3-319-16999-6_2917-1

Sohn, K. 2017. Men's revealed preference for their mates' ages. Evolution and Human Behavior, 38(1): 5862.

Spéder, Z., Murinkó, L., \& Settersten Jr, R. A. 2014. Are conceptions of adulthood universal and unisex? Ages and social markers in 25 European countries. Social Forces, 92(3): 873-898.

Stanojević, D., Tomanović, S., \& Ljubičić, M. 2016. Elements of life satisfaction among young adults in Serbia. Journal of Youth Studies, 19(7): 973-989.

Statistical Office of the Republic of Serbia, 2017. Women and men in the Republic of Serbia.

Statistical Office of the Republic of Serbia. 2020. Statistical release. Population Statistics. Marriages and divorces, 2019. 188, LXX, 10/07/2020.

Taylor, P. A., \& Glenn, N. D. 1976. The utility of education and attractiveness for females' status attainment through marriage. American Sociological Review, 484-498.

Trivers, R. 1972. Parental investment and sexual selection. In B. Campbell (ed.), Sexual Selection \& the Descent of Man, 1871-1971. Aldine de Gruyter, New York, pp. 136-179.

United Nations. 2020. World Economic Situation Prospects. New York.

Walby, S. 2004. The European Union and gender equality: Emergent varieties of gender regime. Social Politics: International Studies in Gender, State \& Society, 11(1): 4-29.

Wiederman, M. W., \& Dubois, S. L. 1998. Evolution and sex differences in preferences for short-term mates: Results from a policy capturing study. Evolution and Human Behavior, 19(3), 153-170.

\section{Figures}




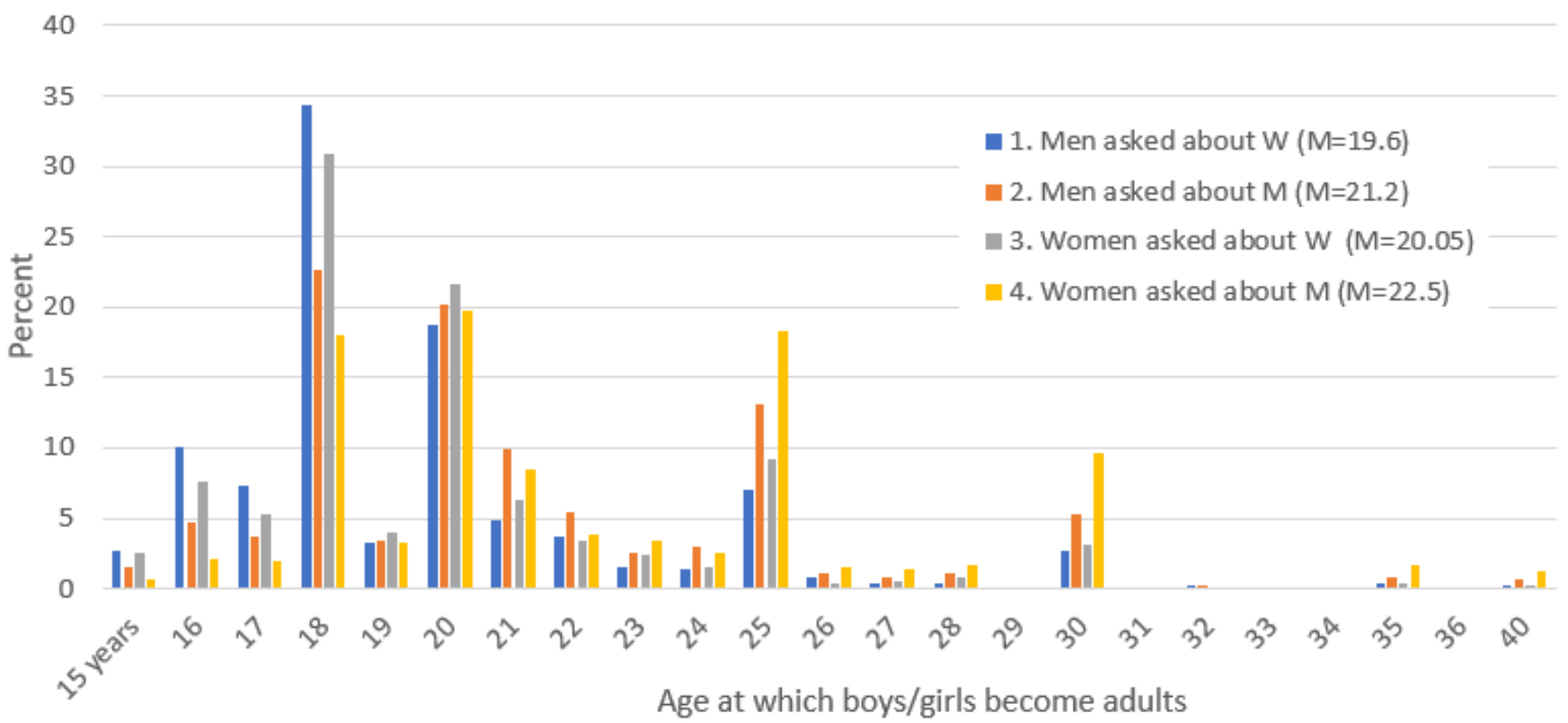

\section{Figure 1}

Distribution of responses concerning the age at which boys/girls become adults by respondent gender

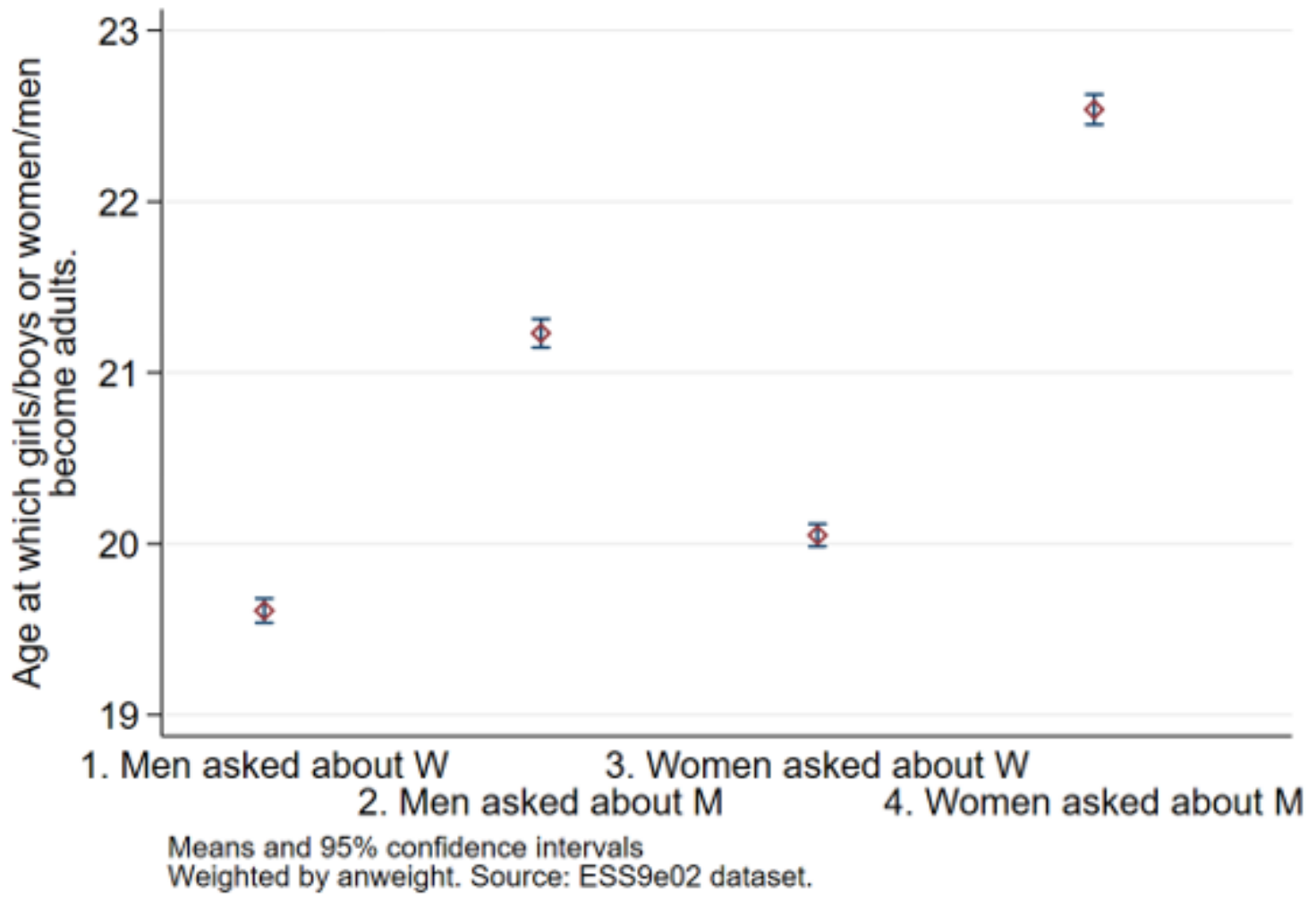

Figure 2 
Average estimates of the age at which girls and boys become adults, separately by male and female respondents

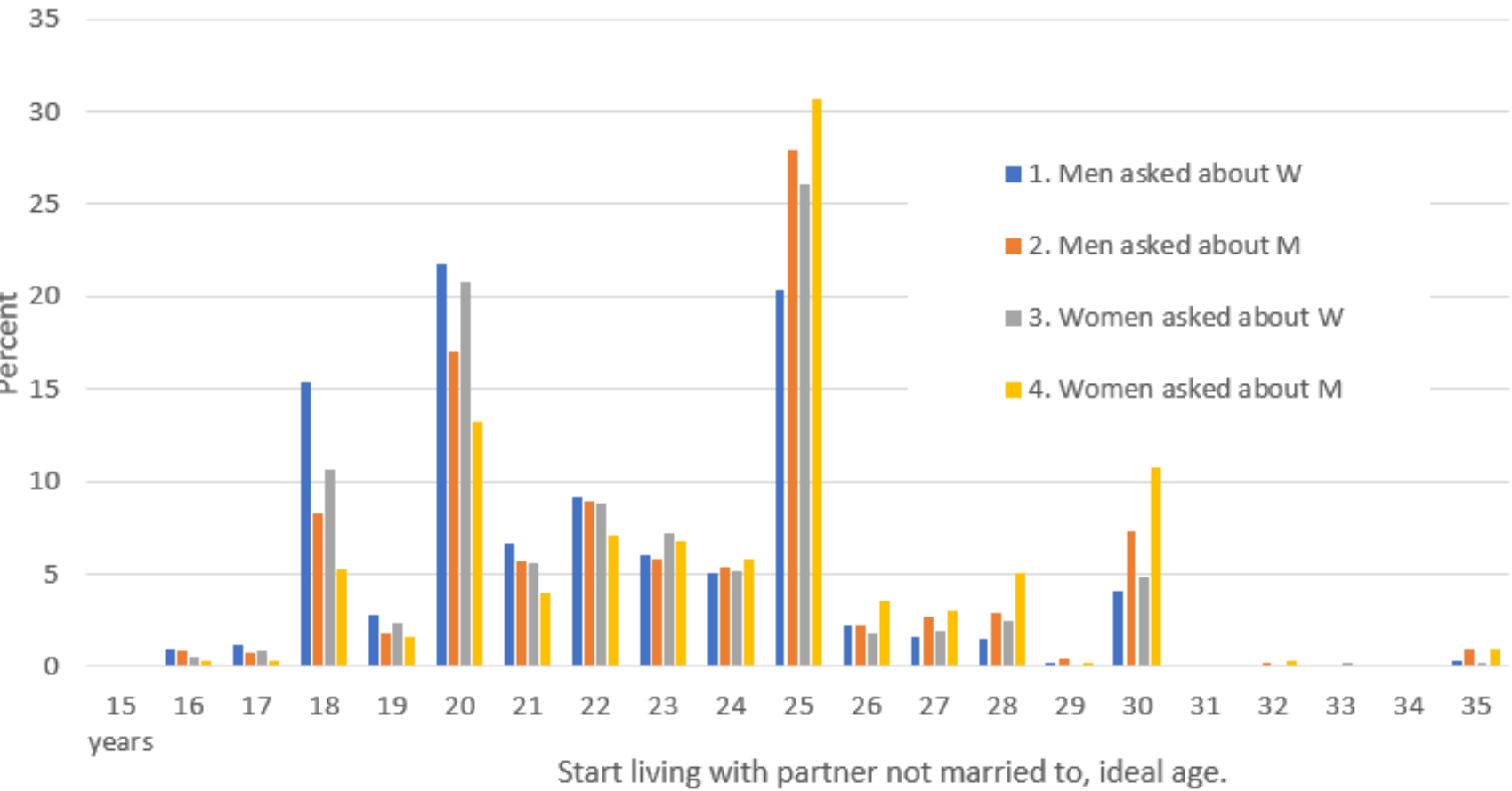

\section{Figure 3}

Distribution of responses to the question about ideal age to start living with a partner not married to

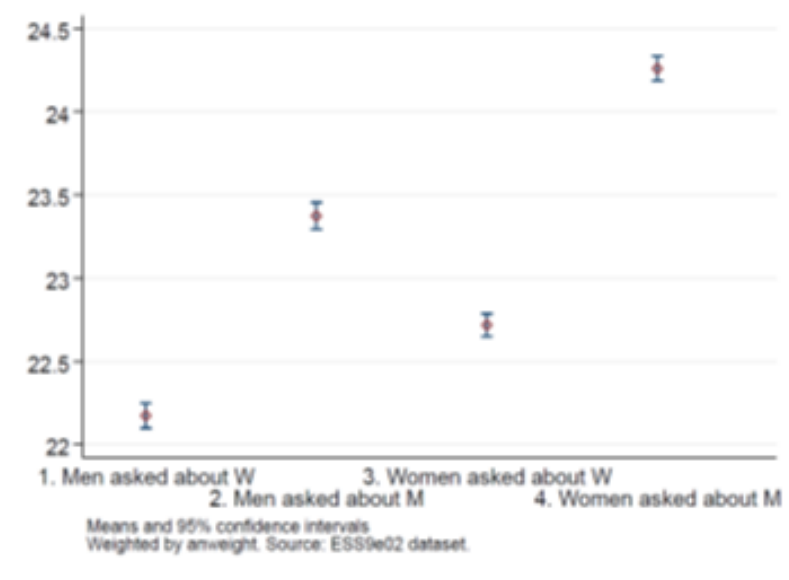

ESS sample

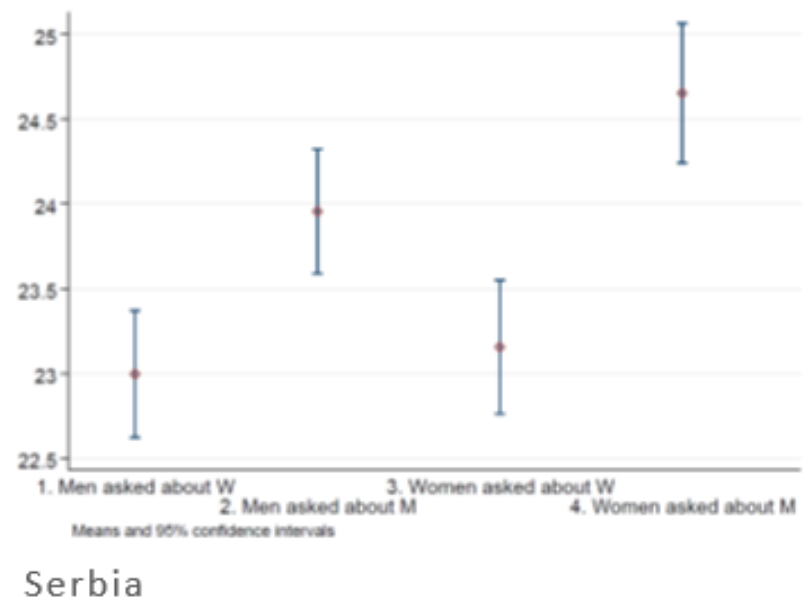

\section{Figure 4}

Ideal age to start living with a partner not married to - European and Serbian data 


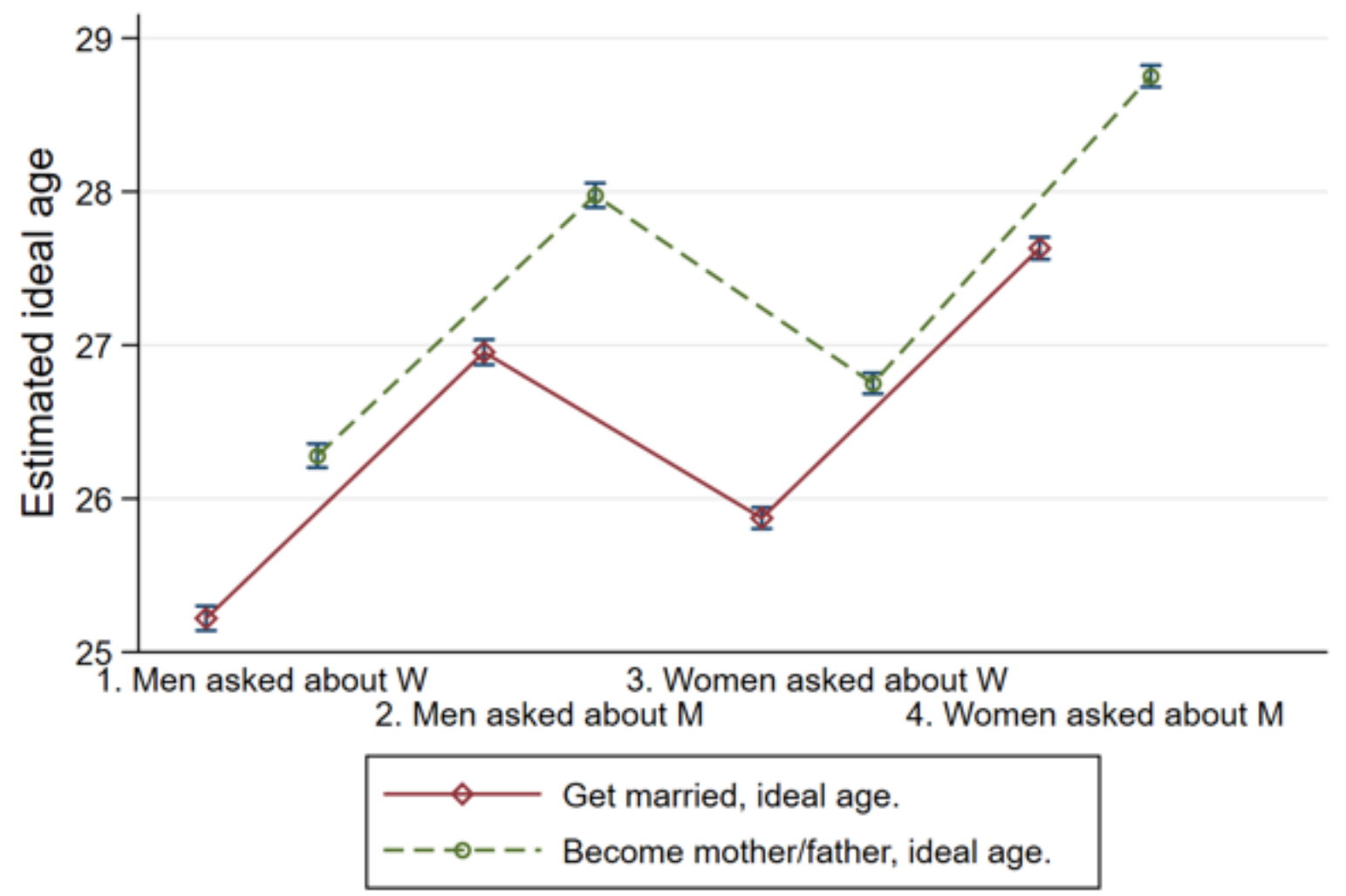

Means and $95 \%$ confidence intervals. Weighted.

\section{Figure 5}

Perceived ideal age to get married and to become parent 

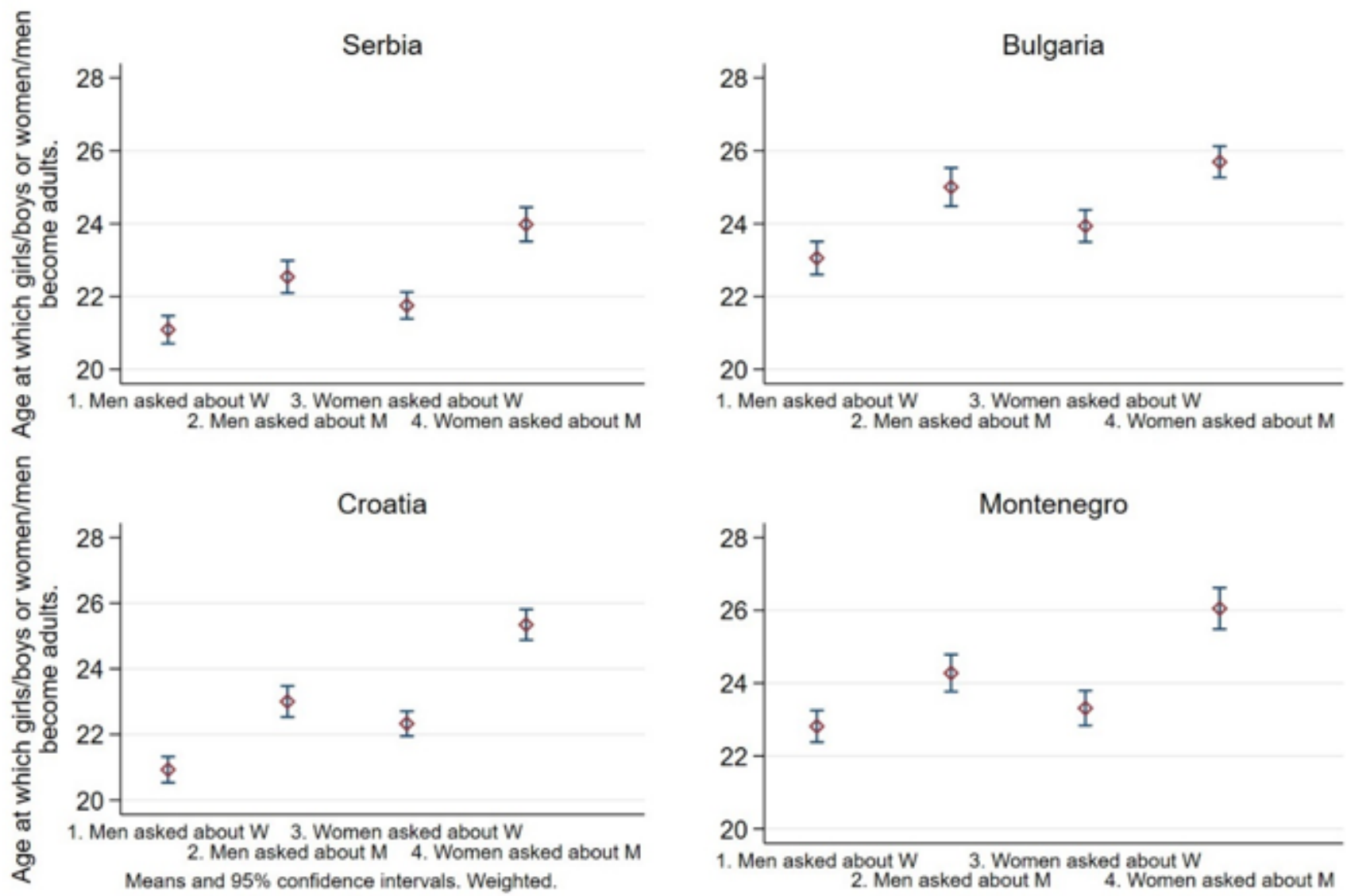

$\begin{array}{ll}\text { 1. Men asked about } W & \text { 3. Women asked about } W \\ \text { 2. Men asked about } M & \text { 4. Women asked about } M\end{array}$

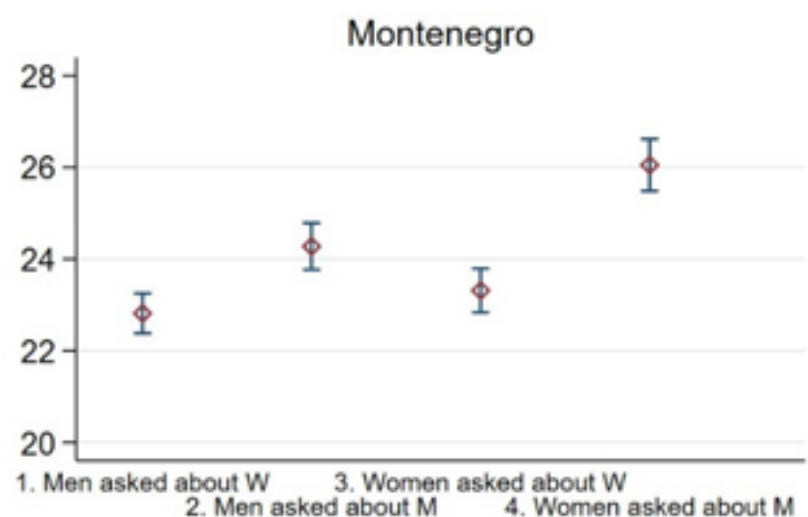

\section{Figure 6}

Gender differences in the Balkan countries 

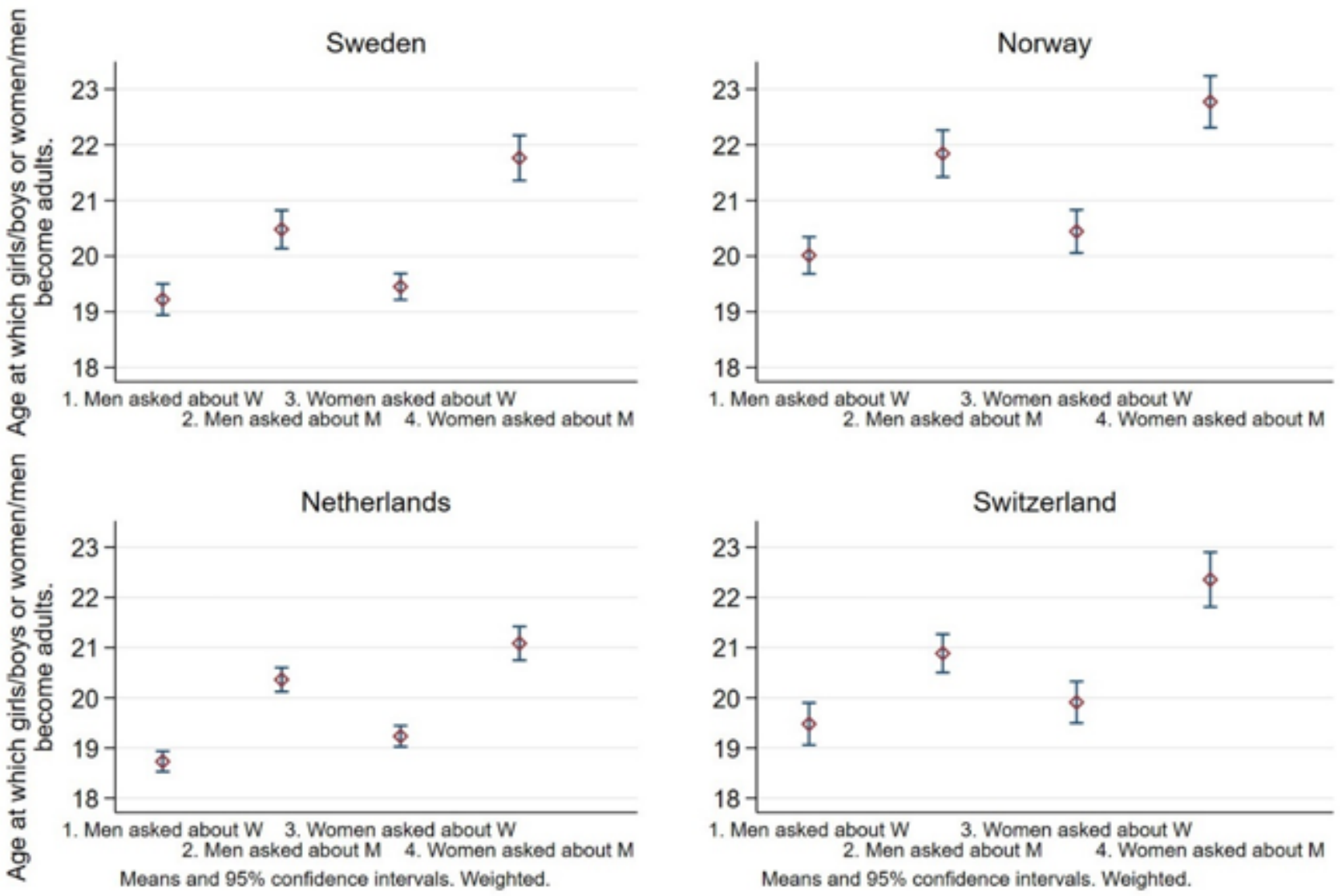

Figure 7

Gender differences in Western-Nordic countries 


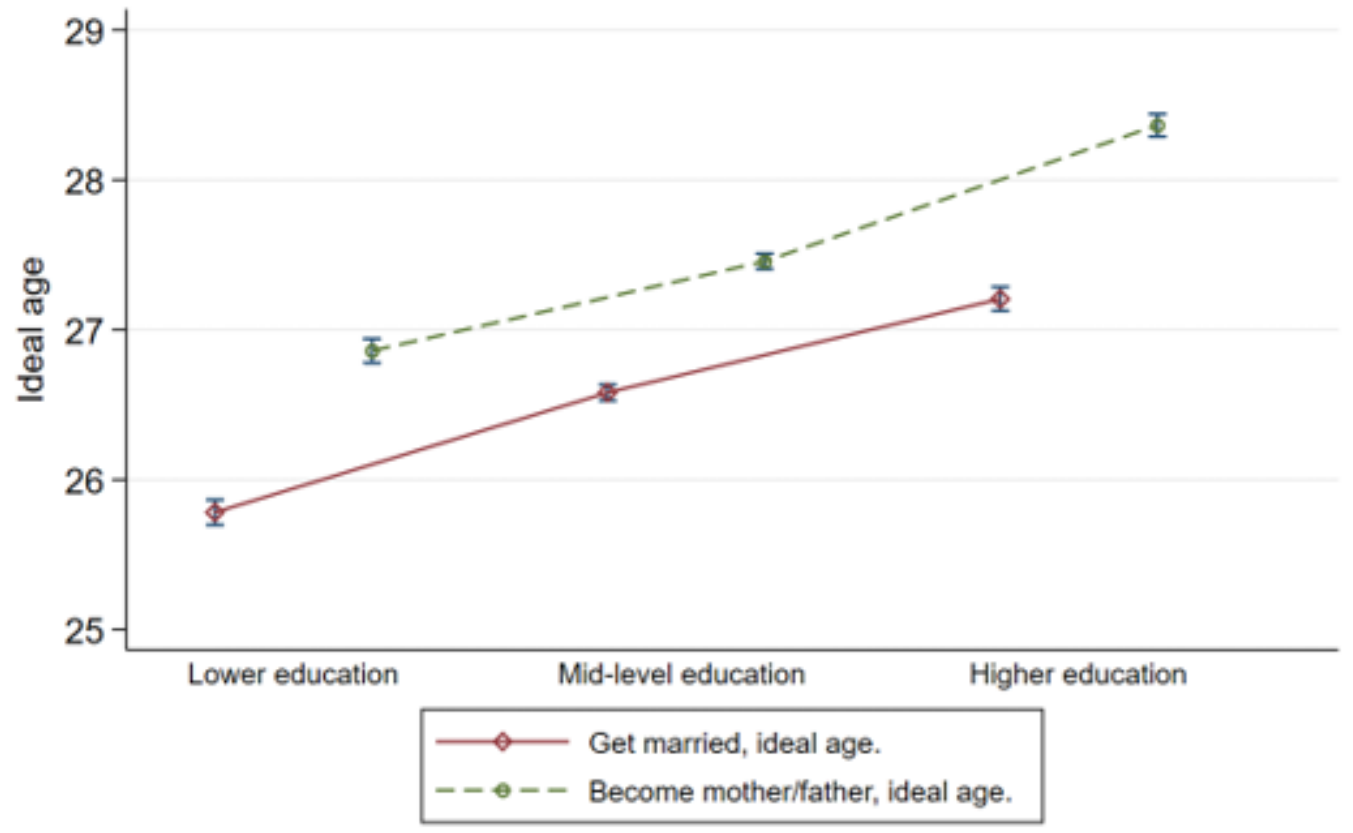

Means and $95 \%$ confidence intervals. Source: ESS9e02 dataset.

\section{Figure 8}

Ideal age assessment in different education categories
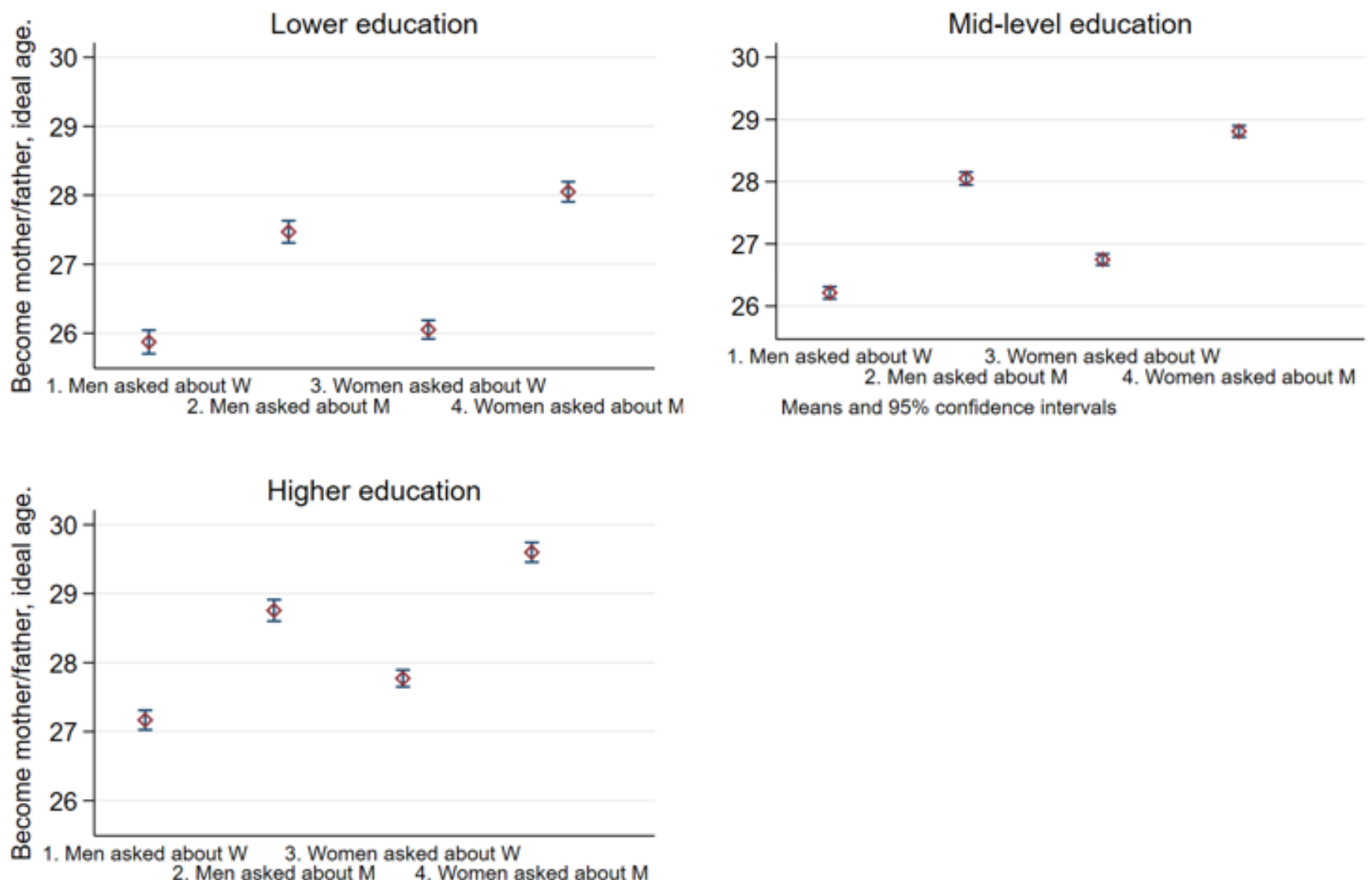
Figure 9

Gender differences in perceptions of ideal age to become a parent in three education categories
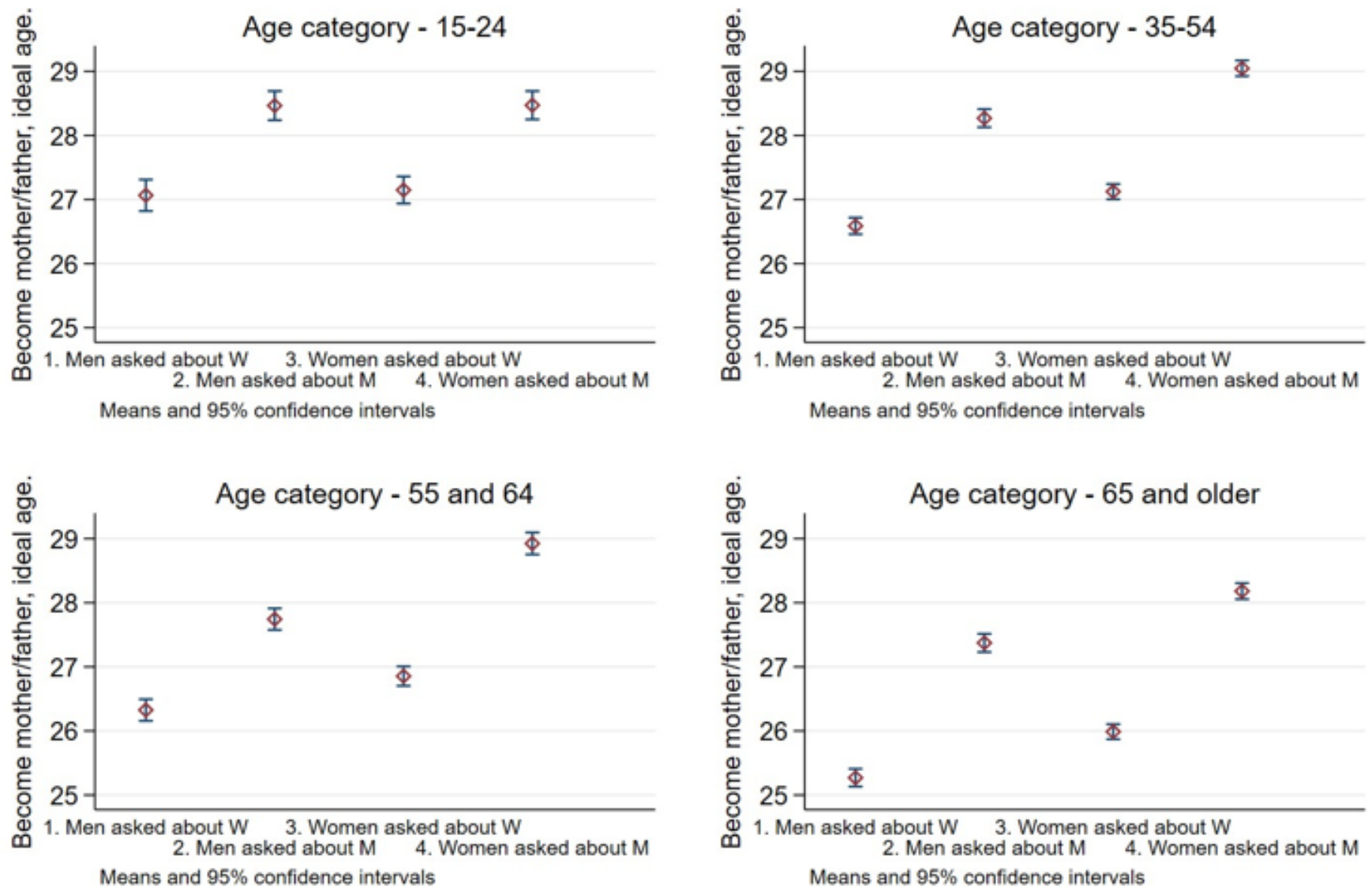

\section{Figure 10}

Gender differences in four age categories 


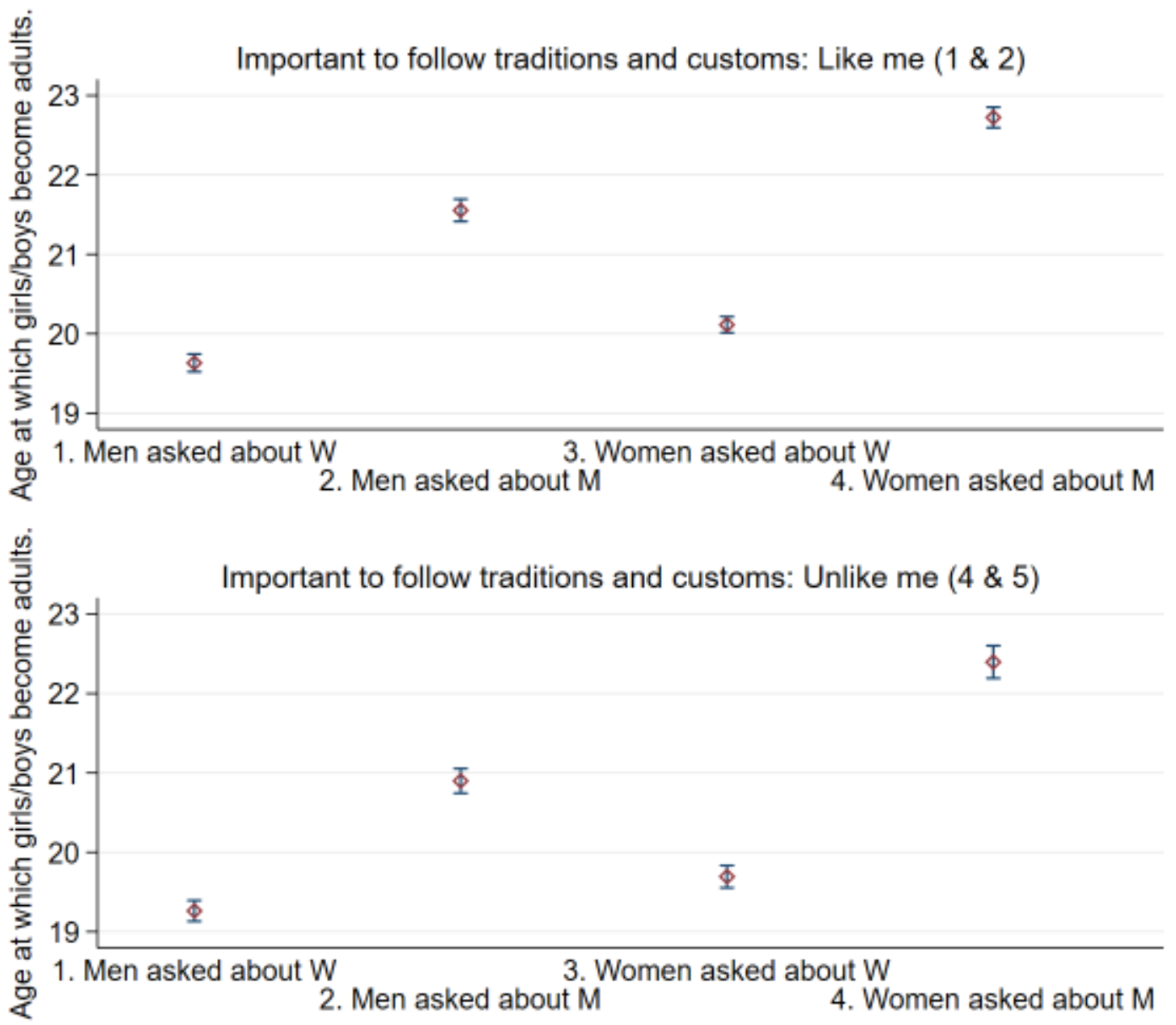

\section{Figure 11}

Influence of traditionalist value orientation onto perception of age at which one becomes adult 

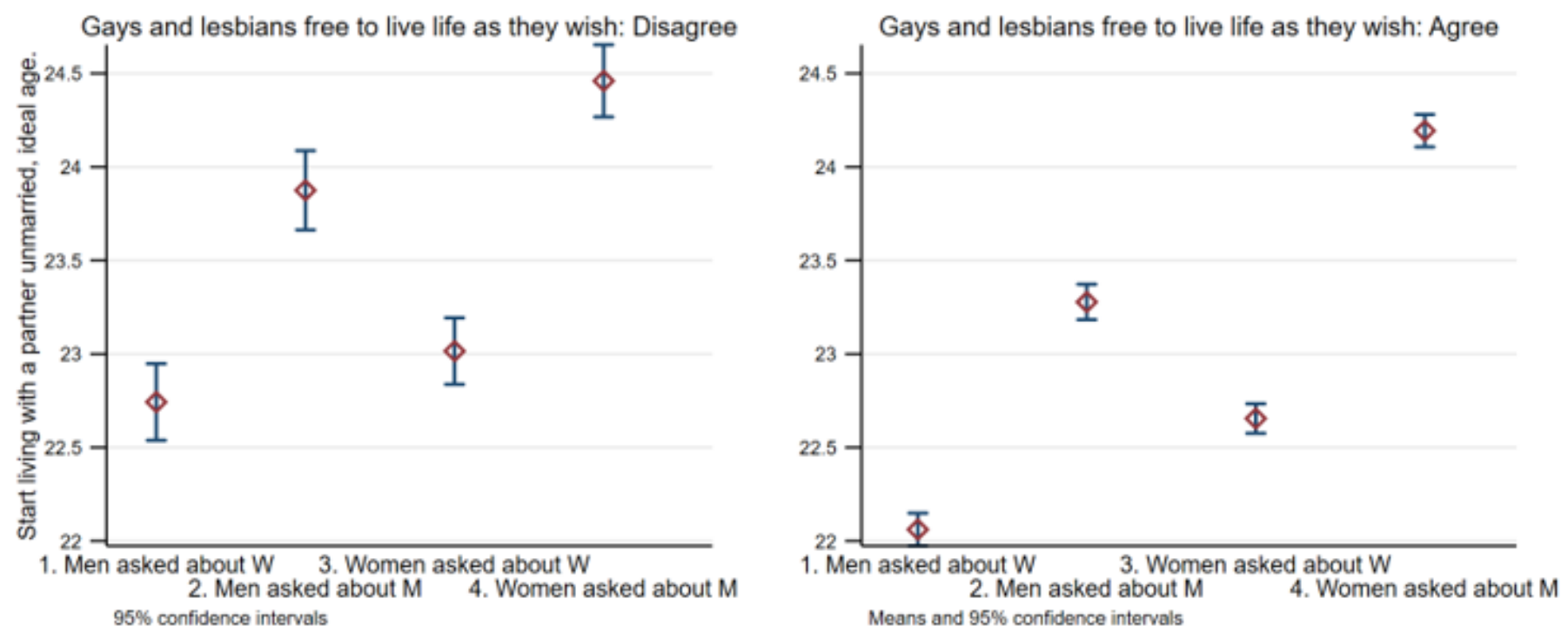

Figure 12

Traditionalism and attitude towards the ideal age to start living with a partner 